\title{
Clinicians' Behavior Toward Radiology Reports: A Cross-Sectional Study
}

Azza S. Reda ${ }^{1}$, Dalia Abdulmonem Hashem ${ }^{1}$, Khalid Khashoggi ${ }^{1}$, Felwa Abukhodair ${ }^{2}$

1. Diagnostic Radiology, King Abdulaziz University, Jeddah, SAU 2. Information Technology, King Abdulaziz University, Jeddah, SAU

Corresponding author: Azza S. Reda, azza.s.reda@gmail.com

Abstract

\section{Background}

The radiology report is the way of communication between the radiologists and the clinicians of different specialties. Each part of the report is important and significant in the patient management plan. Therefore, knowledge of interpretation and behavior in understanding the final report is a variable crucial skill.

\section{Methods}

This is a cross-sectional survey study to explore the behavior and attitude of clinicians toward radiology reports in relation to their professional clinical demographic. A total of 107 physicians participated, including consultants, specialists, and residents among different specialties.

\section{Results}

Among the 107 responses, $58.9 \%$ were male and $41.1 \%$ were female. The majority of the physicians (78.5\%) read the radiology report for every requested study for each patient, while $21.5 \%$ of participants didn't read the radiology report for the studies they requested, instead, they only read it occasionally. Gender played a significant factor, as female practitioners were more likely to read the complete radiology report $(\mathrm{P}=0.033)$. In addition, the age of the practitioner was also significant as clinicians in the age group 40-60 years old were more likely to check the requested radiology image prior to reading the report compared to age groups $20-39$ and $>60$ years $(\mathrm{P}=0.035)$. Lastly, specialists were significantly more likely to read the entire radiology report compared to consultants and residents $(\mathrm{P}=0.006)$.

\section{Conclusion}

More emphasis and awareness should be provided to clinicians on the importance of reading the entire radiology report as some information can be missed if not being read completely.

\section{Review began 10/19/2020 Published 11/05/2020 ๑) Copyright 2020 Reda et al. This is an open access artic distributed under the terms of the Creative Commons Atribution License CC-BY 4.o., which permits unrestricted use, distribution, and reproduction in any source are credited.}

Categories: Radiology

Keywords: reporting physician, clinician, medical errors, communications, radiology report

\section{Introduction}

The radiology report is considered the most important form of communication between the clinicians and the radiologist if not often to be the only method. It is also incorporated as a part of the patient's medical records and plays an essential part in the way clinical care is approached. As the diagnostic process is becoming more complex, radiology reports take on an even more important role [1].

Many studies have evaluated the characteristics and the preferences of both radiologists and other clinicians with regard to radiology reports. Recently, a research study revealed that radiologists preferred a more detailed radiology report that was written in free text (i.e., unstructured), where it also incorporates mentioning of the examination techniques conducted by the radiologist [2]. Another study mentioned the of information, teaching, clinical research, and other related aspects [3]. The aforementioned characteristics and many others form the basis of radiology reports and generate discrepancies regarding the opinions of and many others form the basis of radiology reports and generate discrepancies regarding the opinions of
the best model of a radiology report to be adopted. That being said, the opinion of the referring physician the best model of a radiology report to be adopted. That being said, the opinion of the referring physician
and forming the report in an accurate easy practical language is also of great importance to the process of and forming the report in an accurate easy practical language is also of great importance to th
refining radiology reports, given the fact that they are the final recipients of these reports [4].

In this setting, we conducted the current investigation to study clinicians' behavior regarding the radiology report. We aim to determine how often do clinicians read the radiology report, which part do they most commonly read, how frequently do they check the radiology images before they read the text, and how frequently they make medical errors that could have been easily avoided by reading the report more carefully. This will help shed light on areas of improvement of radiology reporting, how to raise awarenes carefully. This will help shed light on areas of improvement of radiology reporting, how to raise awareness
among clinicians, and reduce potential errors that can be made from either incomplete report reading or misinterpretation.

\section{Materials And Methods}

This is a cross-sectional study, which was approved by the local ethics committee at King Abdul-Aziz University Hospital, Jeddah, Saudi Arabia. A multiple-choice questionnaire was elicited and constructed from previous similar studies $[1,5,6]$. The questionnaire was distributed electronically using the SurveyMonkey website and was distributed through emails to the physicians from 16 various specialties. The study sample included consultants, specialists, and resident physicians. The study was carried out from August 2019 to December 2019 and incomplete data were excluded from the final dataset.

The questionnaire included two parts. The first part consisted of four demographic questions which included gender, age, professional level, and specialty. The second part consisted of four multiple-choice question about clinician behavior toward reading radiology reports. A pilot study was conducted, and the questionnaire showed reliability and validity value of Cronbach's alpha $>0.75$. All 107 responders did not include any personal informations and were completely anonymous. The statistics were analyzed using Statistical Package for the Social Sciences (SPSS 24, IBM Corp., Armonk, NY). A chi-square test of independence was performed to examine the relationship between different independent categorical variables and a P-value of $<0.05$ was considered significant.

\section{Results}

\section{Demographic characteristic}

A total of 107 complete questionnaires were included in the final analysis step. Among the respondents, 63 (58.9\%) were males and $44(41.1 \%)$ were females. The majority of respondents $(70.1 \%)$ were of the age group 20-39 years. Meanwhile, 44 (41.1\%) participants were residents, 40 (37.4\%) were consultants, and $23(21.5 \%)$ were specialists. Included clinicians were of diverse specialties, the pediatric specialty was the most common (24.3\%) followed by internal medicine (18.7\%) and general surgery (14\%). Baseline demographic 


\section{Cureus}

characteristics of included participants are summarized in Table 1 .

\begin{tabular}{|c|c|c|c|}
\hline Variable & Sub-group & Number & Percentage (\%) \\
\hline \multicolumn{4}{|l|}{ Gender } \\
\hline & Male & 63 & 58.9 \\
\hline & Female & 44 & 41.1 \\
\hline \multicolumn{4}{|c|}{ Age group (years) } \\
\hline & $20-39$ & 75 & 70.1 \\
\hline & $40-60$ & 30 & 28 \\
\hline & $>60$ & 2 & 1.9 \\
\hline \multicolumn{4}{|l|}{ Level } \\
\hline & Consultant & 40 & 37.4 \\
\hline & Specialist & 23 & 21.5 \\
\hline & Resident & 44 & 41.1 \\
\hline \multicolumn{4}{|l|}{ Specialty } \\
\hline & General surgery & 15 & 14 \\
\hline & OB \& Gyn & 8 & 7.5 \\
\hline & Orthopedic & 5 & 4.7 \\
\hline & ENT & 3 & 2.8 \\
\hline & ICU & 1 & 0.9 \\
\hline & Pediatrics & 26 & 24.3 \\
\hline & Internal medicine & 20 & 18.7 \\
\hline & Anesthesia & 3 & 2.8 \\
\hline & Emergency & 10 & 9.3 \\
\hline & Neurosurgery & 1 & 0.9 \\
\hline & Urology & 2 & 1.9 \\
\hline & Cardiothoracic & 2 & 1.9 \\
\hline & Plastic surgery & 2 & 1.9 \\
\hline & Ophthalmology & 1 & 0.9 \\
\hline & Family medicine & 3 & 2.8 \\
\hline & Other & 5 & 4.7 \\
\hline
\end{tabular}

TABLE 1: Baseline demographic characteristics of included participants OB \& Gyn: obstetrics and gynecology; ENT: ear, nose and throat; ICU: intensive care unit

\section{Behavior}

A total of 84 clinicians (78.5\%) read the radiology report for every requested examination, while 23 clinicians (21.5\%) read the radiology report occasionally. On the other hand, the majority of respondents, 60 clinicians (56.1\%), reported that they read the entire radiology report, while only $7(6.5 \%)$ read the conclusion part. In the same context, the majority of respondents, $71(66.4 \%)$, reported that they check the radiology images before reading the report itself, while $29(27.1 \%)$ respondents reported checking the radiology images after reading the report. Although the majority of respondents, 68 (63.6\%), never made a medical error that could have been prevented by reading the radiology report, 16 clinicians $(15 \%)$ committed only one medical error
that could have been prevented by reading the report. The same number of 16 clinicians (15\%) made an error that could have been prevented by reading the report. The same number of 16 clinicians $(15 \%)$ made an
two to five times by not reading the entire report carefully. The behaviors of clinicians in reading the two to five times by not reading the entire report caref.
radiology images and reports are presented in Table 2 . 


\section{Cureus}

\begin{tabular}{|c|c|c|c|}
\hline Variable & Sub-category & Number & Percentage \\
\hline \multicolumn{4}{|c|}{ How often do you read the radiology report? } \\
\hline & Every requested examination & 84 & $78.5 \%$ \\
\hline & Occasionally & 23 & $21.5 \%$ \\
\hline \multicolumn{4}{|c|}{ Which part of the radiology report you read? } \\
\hline & Only conclusion & 7 & $6.5 \%$ \\
\hline & The entire report & 60 & $56.1 \%$ \\
\hline & The conclusion and scan through the text & 40 & $37.4 \%$ \\
\hline \multicolumn{4}{|c|}{ Do you check your requested radiology images? } \\
\hline & No & 6 & $5.6 \%$ \\
\hline & Yes (before reading the report) & 71 & $66.4 \%$ \\
\hline & Yes (after reading the report) & 29 & $27.1 \%$ \\
\hline & Missing & 1 & $0.9 \%$ \\
\hline \multicolumn{4}{|c|}{ Have you ever made an avoidable medical error in patient care the } \\
\hline & No, never & 68 & $63.6 \%$ \\
\hline & Yes, once in my entire career & 16 & $15 \%$ \\
\hline & Yes, 2-5 times & 16 & $15 \%$ \\
\hline & Yes, $>5$ times & 7 & $6.5 \%$ \\
\hline
\end{tabular}

The behaviors toward reading the radiology report were then stratified based on gender, age, level, and specialty. We found that females were significantly more likely to read the radiology report for every requested examination compared to males $(88.60 \%$ vs $71.40 \%, \mathrm{P}=0.033)$. Meanwhile, both male and female respondents read the entire radiology report $(55.60 \%$ vs $56.80 \%, \mathrm{P}=0.311)$. We noted no statistically significant differences in the frequency of checking the requested radiology images between both genders ( $\mathrm{P}$ $=0.687$ ) or the number of medical errors that could have been prevented by reading the radiology report more carefully $(\mathrm{P}=0.803)$. Inferential data by gender is presented in Table 3 .

\begin{tabular}{|c|c|c|c|c|c|}
\hline Variable & Sub-category & Total $\mathbf{N}(\%)$ & Male $\mathbf{N}(\%)$ & Female N (\%) & P-value \\
\hline \multicolumn{6}{|c|}{ How often do you read the radiology report? } \\
\hline & Every requested examination & $84(78.5 \%)$ & $45(71.40 \%)$ & $39(88.60 \%)$ & \multirow{2}{*}{$0.033^{\mathrm{a}}$} \\
\hline & Occasionally & $23(21.5 \%)$ & $18(28.60 \%)$ & $5(11.40 \%)$ & \\
\hline \multicolumn{6}{|c|}{ Which part of the radiology report you read? } \\
\hline & Only conclusion & $7(6.5 \%)$ & $6(9.50 \%)$ & $1(2.30 \%)$ & \multirow{3}{*}{0.311} \\
\hline & The entire report & $60(56.1 \%)$ & $35(55.60 \%)$ & $25(56.80 \%)$ & \\
\hline & The conclusion and scan through the text & $40(37.4 \%)$ & $22(34.90 \%)$ & $18(40.90 \%)$ & \\
\hline \multicolumn{6}{|c|}{ Do you check your requested radiology images? } \\
\hline & No & $6(5.6 \%)$ & $3(4.80 \%)$ & $3(7.00 \%)$ & \multirow{3}{*}{$0.6 \mathrm{C}+\mathrm{C}$} \\
\hline & Yes (before reading the report) & $71(66.4 \%)$ & $41(65.10 \%)$ & $30(69.80 \%)$ & \\
\hline & Yes (after reading the report) & $29(27.1 \%)$ & $19(30.20 \%)$ & $10(23.30 \%)$ & \\
\hline \multicolumn{6}{|c|}{ e you ever made an avoidable medic } \\
\hline & No, never & $68(63.6 \%)$ & $38(60.30 \%)$ & $30(68.20 \%)$ & \multirow{4}{*}{0.803} \\
\hline & Yes, once in my entire career & $16(15 \%)$ & $10(15.90 \%)$ & $6(13.60 \%)$ & \\
\hline & Yes, 2-5 times & $16(15 \%)$ & $11(17.50 \%)$ & $5(11.40 \%)$ & \\
\hline & Yes, $>5$ times & $7(6.5 \%)$ & $4(6.30 \%)$ & $3(6.80 \%)$ & \\
\hline
\end{tabular}

TABLE 3: Stratification of clinicians' behavior towards the radiology report by gender ${ }^{a}$ Chi-square test with $\mathrm{P}<0.05$ being statistically significant.

${ }^{b}$ Data for one participant was missing.

Age had no significant factor on how often clinicians read the radiology report $(\mathrm{P}=0.221)$ nor on the frequency of making avoidable medical errors by reading the whole report $(P=0.659)$. On the other hand, gender showed statistical significance toward the frequency of reading reports $(P=0.033)$ with females showing more tendencies to reading the report every time it was requested (Table 3). Clinicians whose age ranges from 40-60 years are significantly more likely to read the entire radiology report compared to age groups $20-39$ and $>60$ years $(70 \%$ vs $50.7 \%$ vs $50 \%, P=0.031)$. In the same context, clinicians in both age groups $20-39$ and $>60$ years compared with clinicians in the age group $40-60$ years are significantly more groups $20-39$ and $>60$ years compared with clinicians in the age group $40-60$ years are significantly more
likely to check the requested radiology image prior to reading the report ( $64 \%$ vs $0 \%$ vs $79.3 \%, P=0.035$ ) (Table 4). 


\section{Cureus}

\begin{tabular}{|c|c|c|c|c|c|}
\hline \multirow{2}{*}{ Variable } & \multirow{2}{*}{ Sub-category } & \multicolumn{3}{|c|}{ Age group (years) N: Numbers (\%) } & \multirow{2}{*}{ P-value } \\
\hline & & 20-39 & $40-60$ & $>60$ & \\
\hline \multicolumn{6}{|c|}{ How often do you read the radiology report? } \\
\hline & Every requested examination & $62(82.70 \%)$ & $21(70.00 \%)$ & $1(50.00 \%)$ & \multirow{2}{*}{0.221} \\
\hline & Occasionally & $13(17.30 \%)$ & $9(30.00 \%)$ & $1(50.00 \%)$ & \\
\hline \multicolumn{6}{|c|}{ Which part of the radiology report you read? } \\
\hline & Only conclusion & $3(4.00 \%)$ & $3(10.00 \%)$ & $1(50.00 \%)$ & \multirow{3}{*}{$0.031^{\mathrm{a}}$} \\
\hline & The entire report & $38(50.70 \%)$ & $21(70.00 \%)$ & $1(50.00 \%)$ & \\
\hline & The conclusion and scan through the text & $34(45.30 \%)$ & $6(20.00 \%)$ & $0(0.00 \%)$ & \\
\hline \multicolumn{6}{|c|}{ Do you check your requested radiology images? $\mathrm{b}$} \\
\hline & No & $6(8.00 \%)$ & $0(0.00 \%)$ & $0(0.00 \%)$ & \multirow{3}{*}{$0.035^{\mathrm{a}}$} \\
\hline & Yes (before reading the report) & $48(64.00 \%)$ & $23(79.30 \%)$ & $0(0.00 \%)$ & \\
\hline & Yes (after reading the report) & $21(28.00 \%)$ & $6(20.70 \%)$ & $2(100.0 \%)$ & \\
\hline \multicolumn{6}{|c|}{ Have you ever made an avoidable medical error in patient care that could have been prevented by reading the radiology report more carefully? } \\
\hline & No, never & $49(65.30 \%)$ & $18(60.00 \%)$ & $1(50.00 \%)$ & \multirow{4}{*}{0.659} \\
\hline & Yes, once in my entire career & $12(16.00 \%)$ & $3(10.00 \%)$ & $1(50.00 \%)$ & \\
\hline & Yes, 2-5 times & $10(13.30 \%)$ & $6(20.00 \%)$ & $0(0.00 \%)$ & \\
\hline & Yes, $>5$ times & $4(5.30 \%)$ & $3(10.00 \%)$ & $0(0.00 \%)$ & \\
\hline
\end{tabular}

TABLE 4: Stratification of clinicians' behavior toward the radiology report by different age groups ${ }^{\mathrm{a} C h i-s q u a r e ~ t e s t ~ w i t h ~} \mathrm{P}<0.05$ being statistically significant.

bData for one participant was missing.

Specialists were significantly more likely to read the entire radiology report compared to consultants and residents ( $87 \%$ vs $55 \%$ vs $40.9 \%, P=0.006$ ). However, comparing different professional levels, the residents were significantly more likely to never make an avoidable medical error that could have been prevented by carefully reading the report ( $45 \%$ vs $69.6 \%$ vs $77.3 \%, \mathrm{P}=0.019)$. Moreover, we noted no statistically significant differences based on how often clinicians read the radiology report $(P=0.742)$ or check the requested images $(P=0.29)$ (Table 5).

\begin{tabular}{|c|c|c|c|c|c|}
\hline \multirow{2}{*}{ Variable } & \multirow{2}{*}{ Sub-category } & \multicolumn{3}{|l|}{ Level } & \multirow{2}{*}{ P-value } \\
\hline & & Consultant & Specialist & Resident & \\
\hline \multicolumn{6}{|c|}{ How often do you read the radiology report? } \\
\hline & Every requested examination & $31(77.50 \%)$ & $17(73.90 \%)$ & $36(81.80 \%)$ & \multirow{2}{*}{0.742} \\
\hline & Occasionally & $9(22.50 \%)$ & $6(26.10 \%)$ & $8(18.20 \%)$ & \\
\hline \multicolumn{6}{|c|}{ Which part of the radiology report you read? } \\
\hline & Only conclusion & $4(10.00 \%)$ & $0(0.00 \%)$ & $3(6.80 \%)$ & \multirow{3}{*}{$0.006^{\mathrm{a}}$} \\
\hline & The entire report & $22(55.00 \%)$ & $20(87.00 \%)$ & $18(40.90 \%)$ & \\
\hline & The conclusion and scan through the text & $14(35.00 \%)$ & $3(13.00 \%)$ & $23(52.30 \%)$ & \\
\hline \multicolumn{6}{|c|}{ Do you check your requested radiology images? ${ }^{b}$} \\
\hline & No & $1(2.60 \%)$ & $0(0.00 \%)$ & $5(11.40 \%)$ & \multirow{3}{*}{0.29} \\
\hline & Yes (before reading the report) & $28(71.80 \%)$ & $16(69.60 \%)$ & $27(61.40 \%)$ & \\
\hline & Yes (after reading the report) & $10(25.60 \%)$ & $7(30.40 \%)$ & $12(27.30 \%)$ & \\
\hline \multicolumn{6}{|c|}{ Have you ever made an avoidable medical error in patient care that could have been prevented by reading the radiology report more carefully? } \\
\hline & No, never & $18(45.00 \%)$ & $16(69.60 \%)$ & $34(77.30 \%)$ & \multirow{4}{*}{$0.019^{\mathrm{a}}$} \\
\hline & Yes, once in my entire career & $6(15.00 \%)$ & $5(21.70 \%)$ & $5(11.40 \%)$ & \\
\hline & Yes, 2-5 times & $11(27.50 \%)$ & $1(4.30 \%)$ & $4(9.10 \%)$ & \\
\hline & Yes, $>5$ times & $5(12.50 \%)$ & $1(4.30 \%)$ & $1(2.30 \%)$ & \\
\hline
\end{tabular}

TABLE 5: Stratification of clinicians' behavior toward the radiology report by different professional level

${ }^{a}$ Chi-square test with $\mathrm{P}<0.05$ being statistically significant.

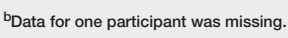

The professional level significantly affected which part of the radiology is being read $(\mathrm{P}=0.006)$. Finally, due to the small number of participants in each specialty, such as intensive care unit (ICU), ear, nose and throat (ENT), neurosurgery, ophthalmology, and plastic surgery $(1,3,1,1$ and 2 , respectively), making inferential statistics was inapplicable. The differences in making avoidable medical errors that could have been prevented by carefully reading the radiology report were then pooled against which part of the been prevented by carefully reading the radiology report were then pooled against which part of the
radiology report is most often read. However, we noted no statistically significant differences between the 


\section{Cureus}

different groups $(P=0.749)$ (Table $)$. Furthermore, changes in the behaviors of reading the radiology report or committing medical errors based on specialty are presented in the appendices (Table 7 ).

\begin{tabular}{|c|c|c|c|c|c|c|c|c|}
\hline & & & \multicolumn{4}{|c|}{$\begin{array}{l}\text { Have you ever made an avoidable medical error in patient care that } \\
\text { could have been prevented by reading the radiology report more } \\
\text { carefully? }\end{array}$} & \multirow[t]{2}{*}{ Total } & \multirow[t]{2}{*}{$\begin{array}{l}\text { P- } \\
\text { value }\end{array}$} \\
\hline & & & No, never & Yes, once in my entire career & Yes, 2-5 times & Yes, $>5$ times & & \\
\hline \multirow{6}{*}{$\begin{array}{l}\text { Which part of the } \\
\text { radiology report you } \\
\text { read? }\end{array}$} & Only conclusion & $\mathrm{N}$ & 6 & 0 & 1 & 0 & 7 & \multirow{8}{*}{0.749} \\
\hline & & $\%$ & $85.7 \%$ & $0.0 \%$ & $14.3 \%$ & $0.0 \%$ & $100.0 \%$ & \\
\hline & & $\mathrm{N}$ & 35 & 11 & 9 & 5 & 60 & \\
\hline & & $\%$ & $58.3 \%$ & $18.3 \%$ & $15.0 \%$ & $8.3 \%$ & $100.0 \%$ & \\
\hline & $\begin{array}{l}\text { The conclusion and } \\
\text { scan through the }\end{array}$ & $\mathrm{N}$ & 27 & 5 & 6 & 2 & 40 & \\
\hline & text & $\%$ & $67.5 \%$ & $12.5 \%$ & $15.0 \%$ & $5.0 \%$ & $100.0 \%$ & \\
\hline \multirow{2}{*}{ Total } & & $\mathrm{N}$ & 68 & 16 & 16 & 7 & 107 & \\
\hline & & $\%$ & $63.6 \%$ & $15.0 \%$ & $15.0 \%$ & $6.5 \%$ & $100.0 \%$ & \\
\hline
\end{tabular}

TABLE 6: Changes in making avoidable medical errors by different parts of the radiology report

TABLE

\section{Discussion}

The radiology report is usually the communication method between radiologists and clinicians. Therefore, it is crucial for radiology reports to be sufficient and adequate enough to fulfill their clinical question. In our study, we asked the clinicians about their behavior of reading the requested radiographic reports and reviewing the images. We wanted to determine how often clinicians read the radiology report, which parts of the report they read the most, how frequently they check requested images, and how frequently they make the report they read the most, how frequently they check requested images, and how frequently they make
medical errors that could have been avoided by carefully going through the radiology report. Moreover, we medical errors that could have been avoided by carefully going through the radiology report. Moreover, wC
wanted to determine whether these behaviors change based on a set of demographic characteristics, including age, gender, professional level, and specialty.

The majority of our population (78.5\%) reported reading the report for every requested examination. However, only $56.1 \%$ of the entire population reported reading the full report and $37.4 \%$ of participants stated that they read the conclusion and skim through the report for further information regarding the findings. Also, $66.4 \%$ of the participants checked the requested images before reading the text of the report. The majority of participants $(63.6 \%)$ had not committed any errors in relation to not reading the report. A similar study was conducted in 2013 on 102 clinicians. The study showed that $69 \%$ of clinicians read the similar study was conducted in 2013 on 102 clinicians. The study showed that $69 \%$ of clinicians read the entire report while only $33 \%$ of clinicians admitted to committing one or more medical errors that could
have been prevented by reading the entire report [6]. Furthermore, a similar research study published in 2018 , investigated the opinion of the referring physician with regards to the radiology report on 70 healthcare worker with $45.7 \%$ of which were clinicians [1]. The study reported that $55.7 \%$ of referring physicians read the radiology report in full, which is almost the same as our reported percentage of $56.1 \%$. Moreover, in the previous study, $67.1 \%$ of physicians preferred that the radiology report would be structured, and $75.7 \%$ preferred if the conclusion section of the report would incorporate a list of the various diagnostic possibilities. Moreover, a research study was conducted at a public and a university hospital to evaluate the expectations of clinicians. The study showed that the majority of clinicians $(70.5 \%)$ preferred if a recommendation section was provided at the end of the report, which would have helped them understand the report more $[5,7]$. This would significantly help clinicians easily reach the definitive diagnosis by combining the data of the radiology report with the clinical presentation and examination of each patient combining the data of the radiology report with the clinical presentation and examination of each patient
$[1,8,9]$. Based on the aforementioned observations, it is important to form a relevant and convenient $[1,8,9]$. Based on the aforementioned observations, it is important to form a relevant and convenient
conclusion section in the radiology report, given that a representative number of clinicians do not read the conclusion section in the radiology report, given that a representative number of clinicians do
report fully, as we found in our research that $6.5 \%$ of the physician read only the conclusion.

In this study, we found that female physicians were more likely to read the full radiology report (56.80\%) compared to male peers $(55.60 \%$ ). We also noted that physicians within the age group of $40-60$ years were significantly more likely to read the entire report and to check the requested images before reading the report text compared report text compad to the age geups (20-39 or $>60$ years). Specialists, in our study, were significantly commit any medical errors that could have been easily avoided by carefully going through the radiology commit any medical errors that could have been easily avoided by carefully going through the radiology
report. This can be attributed to the fact that they are more careful in reading reports as they are still under report. This can be attributed to the fact that they are more careful in reading reports as they are still und
training. Some studies suggest that the role of the training program itself can contribute to decreasing medical errors in general [10-12]. Naveh et al. stated that decreasing medical errors, in general, is reduced to the fact that residents tend to seek more senior help [13].

Lastly, the age of the clinicians had a significant impact on reading the radiology report where the older the that attending physicians, who their mean age was 76.5 and 52 for males and females, respectively, spent less time reading the entire report in comparison to residents [14]. This can further support the fact that residents under training try to avoid medical errors as much as possible due to their limited experience compared to seniors. Interestingly, the age of the practitioner was also significant as the age group of 40-60 years of age were more likely to check the requested radiology image prior to reading the report compared to age groups $20-39$ and $>60$ years $(P=0.035)$. This is yet to be explored for future studies as to the best of our knowledge no other study explored this area. However, we hypothesize that at the early career stages, clinicians often learn from their mistakes and start paying more attention to details until they reach a peak of report reading in the middle stage of their careers. Afterward, it starts declining as experience plays a role in gaining more confidence in reading the reports.

Due to the significant diversity of specialties of included participants, we couldn't make inferential statistics related to the differences in behaviors toward report reading. We also examined whether the frequency of committing medical errors would have changed according to which part of the radiology report is often read by the referring physician. However, we found no statistically significant differences among the studied groups.

Despite the fact that some diagnoses may be missed due to some technical or physical limiting factors related to the imaging modality, including imaging resolution, contrast, and signal-to-noise ratio, the majority of errors are attributable to under-reading of the radiology report is $(42 \%)$ [15,16]. In our study, we majority of errors are attributable to under-reading of the radiology report is $(42 \%)[15,16]$. In our study,
noted that $43.9 \%$ of physicians read the conclusion section only or skim through the report for relevant noted that $43.9 \%$ of physicians read the conclusion section only or skim through the report for relevant
findings. This may lead to a significant increase in the rate of attributable medical errors. We also noted that findings. This may lead to a significant increase in the rate of attributable medical errors. We also noted that
$36.5 \%$ of our population committed medical errors (more than once) that could have been easily avoided by 


\section{Cureus}

carefully going through the report. Therefore, based on our study's results it is recommended to read the entire radiology report prior to
initiating the treatment plan. Also, writing the conclusion of the report in very short and brief sentences might motivate clinicians to read the whole report. Furthermore, writing phrases in the summary such as see might motivate clinicians to read the whole report. Furthermore, writing phrases in the summary such as see above will also give physicians reason to go through the entire report. Lasty
making it not sufficient enough should be studied further in the future.

Even though we performed epidemiological analyses based on age, gender, professional level, and specialty to examine any disparities among them, our study has certain limitations. The most important of which is the relatively small sample size of our study which took place in one hospital setting. These limitations me it diffilt to resh a statistical significa made it dived having a big numer statistics between apecities between each specialty behavior. Furthermore, similar studies have been more likely to explore the structure of the report rather than the behavior itself so we couldn't compare a lot of our results with the literature. Therefore, our findings should be interpreted with caution and not be considered representative of the general population. Prospective studies with larger sample sizes are still warranted to confirm our findings.

\section{Conclusions}

In conclusion, gender, age, and training level played a big role in affecting the behavior toward how a radiology report is read. Building awareness toward clinicians on the importance of reading the whole radiology report is necessary to avoid medical errors in the future. However, more studies should be carried out to compare the behaviors of clinicians from various specialties toward reading the radiology report.

\section{Appendices}

\begin{tabular}{|c|c|c|c|c|c|c|c|c|c|c|c|c|c|c|c|}
\hline \multirow{2}{*}{ Variable } & \multirow{2}{*}{$\begin{array}{l}\text { Sub- } \\
\text { category }\end{array}$} & \multicolumn{14}{|l|}{ Specialty } \\
\hline & & $\begin{array}{l}\text { General } \\
\text { Surgery }\end{array}$ & $\begin{array}{l}\text { OB \& } \\
\text { GYN }\end{array}$ & Orthopedic & ENT & ICU & Pediatrics & $\begin{array}{l}\text { Internal } \\
\text { Medicine }\end{array}$ & Anesthesia & Emergency & Neurosurgery & Urology & Cardiothoracic & $\begin{array}{l}\text { Plastic } \\
\text { Surgery }\end{array}$ & Ophtha \\
\hline \multicolumn{16}{|c|}{ How often do you read the radiology report? } \\
\hline & $\begin{array}{l}\text { Every } \\
\text { requested } \\
\text { exam }\end{array}$ & $\begin{array}{l}14 \\
(93.30 \%)\end{array}$ & $\begin{array}{l}7 \\
(87.50 \%)\end{array}$ & $2(40.00 \%)$ & $3(100 \%)$ & $\begin{array}{l}1 \\
(100 \%)\end{array}$ & $\begin{array}{l}21 \\
(80.80 \%)\end{array}$ & $\begin{array}{l}17 \\
(85.00 \%)\end{array}$ & $2(66.70 \%)$ & $7(70.00 \%)$ & $0(0.00 \%)$ & $\begin{array}{l}1 \\
(50.00 \%)\end{array}$ & $0(0.00 \%)$ & $(100.00 \%)$ & 1 (100.c \\
\hline & Occasionally & $\begin{array}{l}1 \\
(6.70 \%)\end{array}$ & $\begin{array}{l}1 \\
(12.50 \%)\end{array}$ & $3(60.00 \%)$ & $\begin{array}{l}0 \\
(0.00 \%)\end{array}$ & $\begin{array}{l}0 \\
(0.00 \%)\end{array}$ & $\begin{array}{l}5 \\
(19.20 \%)\end{array}$ & $\begin{array}{l}3 \\
(15.00 \%)\end{array}$ & $1(33.30 \%)$ & $3(30.00 \%)$ & $1(100.00 \%)$ & $\begin{array}{l}1 \\
(50.00 \%)\end{array}$ & $2(100.00 \%)$ & $0(0.00 \%)$ & $0\left(0.00^{\circ}\right.$ \\
\hline \multicolumn{16}{|c|}{ Which part of the radiology report you read? } \\
\hline & $\begin{array}{l}\text { Only } \\
\text { Conclusion }\end{array}$ & $\begin{array}{l}1 \\
(6.70 \%)\end{array}$ & $\begin{array}{l}1 \\
(12.50 \%)\end{array}$ & $0(0.00 \%)$ & $\begin{array}{l}1 \\
(33.30 \%)\end{array}$ & $\begin{array}{l}0 \\
(0.00 \%)\end{array}$ & $1(3.80 \%)$ & $\begin{array}{l}0 \\
(0.00 \%)\end{array}$ & $0(0.00 \%)$ & $1(10.00 \%)$ & $0(0.00 \%)$ & $\begin{array}{l}0 \\
(0.00 \%)\end{array}$ & $1(50.00 \%)$ & $0(0.00 \%)$ & $0\left(0.00^{\circ}\right.$ \\
\hline & $\begin{array}{l}\text { The entire } \\
\text { report }\end{array}$ & $\begin{array}{l}11 \\
(73.30 \%)\end{array}$ & $\begin{array}{l}5 \\
(62.50 \%)\end{array}$ & $4(80.00 \%)$ & $\begin{array}{l}0 \\
(0.00 \%)\end{array}$ & $\begin{array}{l}1 \\
(100 \%)\end{array}$ & $\begin{array}{l}14 \\
(53.80 \%)\end{array}$ & $\begin{array}{l}8 \\
(40.00 \%)\end{array}$ & $2(66.70 \%)$ & $5(50.00 \%)$ & $1(100 \%)$ & $2(100 \%)$ & $1(50.00 \%)$ & $\begin{array}{l}2 \\
(100.00 \%)\end{array}$ & $0\left(0.00^{\circ}\right.$ \\
\hline & $\begin{array}{l}\text { The } \\
\text { conclusion } \\
\text { and scan } \\
\text { through the } \\
\text { text }\end{array}$ & $\begin{array}{l}3 \\
(20.00 \%)\end{array}$ & $\begin{array}{l}2 \\
(25.00 \%)\end{array}$ & $1(20.00 \%)$ & $\begin{array}{l}2 \\
(66.70 \%)\end{array}$ & $\begin{array}{l}0 \\
(0.00 \%)\end{array}$ & $\begin{array}{l}11 \\
(42.30 \%)\end{array}$ & $\begin{array}{l}12 \\
(60.00 \%)\end{array}$ & $1(33.30 \%)$ & $4(40.00 \%)$ & $0(0.00 \%)$ & $\begin{array}{l}0 \\
(0.00 \%)\end{array}$ & $0(0.00 \%)$ & $0(0.00 \%)$ & 1 (100\% \\
\hline \multicolumn{16}{|c|}{ Do you check your requested radiology images?a } \\
\hline & No & $\begin{array}{l}1 \\
(6.70 \%)\end{array}$ & $\begin{array}{l}1 \\
(12.50 \%)\end{array}$ & $0(0.00 \%)$ & $\begin{array}{l}0 \\
(0.00 \%)\end{array}$ & $\begin{array}{l}0 \\
(0.00 \%)\end{array}$ & $2(7.70 \%)$ & $\begin{array}{l}1 \\
(5.00 \%)\end{array}$ & $1(33.30 \%)$ & $0(0.00 \%)$ & $0(0.00 \%)$ & $\begin{array}{l}0 \\
(0.00 \%)\end{array}$ & $0(0.00 \%)$ & $0(0.00 \%)$ & $0\left(0.00^{\circ}\right.$ \\
\hline & $\begin{array}{l}\text { Yes (Before } \\
\text { reading the } \\
\text { report) }\end{array}$ & $\begin{array}{l}11 \\
(73.30 \%)\end{array}$ & $\begin{array}{l}2 \\
(25.00 \%)\end{array}$ & $5(100 \%)$ & $\begin{array}{l}2 \\
(66.70 \%)\end{array}$ & $\begin{array}{l}1 \\
(100 \%)\end{array}$ & $\begin{array}{l}17 \\
(65.00 \%)\end{array}$ & $\begin{array}{l}13 \\
(65.00 \%)\end{array}$ & $2(66.70 \%)$ & $8(80.00 \%)$ & $1(100 \%)$ & $2(100 \%)$ & $2(100 \%)$ & $0(0.00 \%)$ & 1 (100\% \\
\hline & $\begin{array}{l}\text { Yes (After } \\
\text { reading the } \\
\text { report) }\end{array}$ & $\begin{array}{l}3 \\
(20.00 \%)\end{array}$ & $\begin{array}{l}5 \\
(62.50 \%)\end{array}$ & $0(0.00 \%)$ & $\begin{array}{l}1 \\
(33.30 \%)\end{array}$ & $\begin{array}{l}0 \\
(0.00 \%)\end{array}$ & $\begin{array}{l}7 \\
(26.90 \%)\end{array}$ & $\begin{array}{l}6 \\
(30.00 \%)\end{array}$ & $0(0.00 \%)$ & $2(20.00 \%)$ & $0(0.00 \%)$ & $\begin{array}{l}0 \\
(0.00 \%)\end{array}$ & $0(0.00 \%)$ & $2(100 \%)$ & $0\left(0.00^{\circ}\right.$ \\
\hline \multicolumn{16}{|c|}{ Have you ever made an avoidable medical error in patient care that could have been prevented by reading the radiology report more carefully? } \\
\hline & No, never & $\begin{array}{l}11 \\
(73.30 \%)\end{array}$ & $\begin{array}{l}5 \\
(62.50 \%)\end{array}$ & $5(100 \%)$ & $3(100 \%)$ & $\begin{array}{l}0 \\
(0.00 \%)\end{array}$ & $\begin{array}{l}16 \\
(61.50 \%)\end{array}$ & $\begin{array}{l}11 \\
(55.00 \%)\end{array}$ & $2(66.70 \%)$ & $3(30.00 \%)$ & $1(100 \%)$ & $\begin{array}{l}1 \\
(50.00 \%)\end{array}$ & $2(100 \%)$ & $\begin{array}{l}1 \\
(50.00 \%)\end{array}$ & $1(100 \%$ \\
\hline & $\begin{array}{l}\text { Yes, once in } \\
\text { my entire } \\
\text { career }\end{array}$ & $\begin{array}{l}3 \\
(20.00 \%)\end{array}$ & $\begin{array}{l}0 \\
(0.00 \%)\end{array}$ & $.00 \%)$ & $\begin{array}{l}0 \\
(0.00 \%)\end{array}$ & $\begin{array}{l}1 \\
(100 \%)\end{array}$ & $(7.70 \%)$ & $\begin{array}{l}6 \\
(30.00 \%)\end{array}$ & $1(33.30 \%)$ & $1(10.00 \%)$ & $0(0.00 \%)$ & $\begin{array}{l}1 \\
(50.00 \%)\end{array}$ & $0(0.00 \%)$ & $\begin{array}{l}1 \\
(50.00 \%)\end{array}$ & $0\left(0.00^{\circ}\right.$ \\
\hline & $\begin{array}{l}\text { Yes, 2-5 } \\
\text { times }\end{array}$ & $\begin{array}{l}1 \\
(6.70 \%)\end{array}$ & $\begin{array}{l}1 \\
(12.50 \%)\end{array}$ & $0.00 \%)$ & $\begin{array}{l}0 \\
(0.00 \%)\end{array}$ & $\begin{array}{l}0 \\
(0.00 \%)\end{array}$ & $\begin{array}{l}6 \\
(23.10 \%)\end{array}$ & $\begin{array}{l}2 \\
(10.00 \%)\end{array}$ & $0(0.00 \%)$ & $4(40.00 \%)$ & $0(0.00 \%)$ & $\begin{array}{l}0 \\
(0.00 \%)\end{array}$ & $0(0.00 \%)$ & $0(0.00 \%)$ & $0\left(0.00^{\circ}\right.$ \\
\hline & $\begin{array}{l}\text { Yes, }>5 \\
\text { times }\end{array}$ & $\begin{array}{l}0 \\
(0.00 \%)\end{array}$ & $\begin{array}{l}2 \\
(25.00 \%)\end{array}$ & . $00 \%)$ & $\begin{array}{l}0 \\
(0.00 \%)\end{array}$ & $\begin{array}{l}0 \\
(0.00 \%)\end{array}$ & $2(7.70 \%)$ & $\begin{array}{l}1 \\
(5.00 \%)\end{array}$ & $0(0.00 \%)$ & $2(20.00 \%)$ & $0(0.00 \%)$ & $\begin{array}{l}0 \\
(0.00 \%)\end{array}$ & $0(0.00 \%)$ & $0(0.00 \%)$ & $0\left(0.00^{\circ}\right.$ \\
\hline
\end{tabular}

TABLE 7: Stratification of clinicians' behavior towards the radiology report by specialty a Data of one participant is missing.

OB \& Gyn: obstetrics and gynecology; ENT: ear, nose and throat; ICU: intensive care unit

Additional Information

Disclosures

Human subjects: Consent was obtained by all participants in this study. King Abdulaziz University Hospital IRB issued approval NA. Animal subjects: All authors have confirmed that this study did not involve animal subjects or tissue. Conflicts of interest: In compliance with the ICMJE uniform disclosure form, all authors declare the following: Payment/services info: All authors have declared that no financial support was 


\section{Cureus}

received from any organization for the submitted work. Financial relationships: All authors have declared that they have no financial relationships at present or within the previous three years with any organizations that might have an interest in the submitted work. Other relationships: All authors have declared that there are no other relationships or activities that could appear to have influenced the submitted work.

\section{References}

1. Ignácio FdCGR, de Souza LRMF, D'Ippolito G, Garcia MM: Radiology report: what is the opinion of the referring physician?. Radiol Bras. 2018, 51:308-312. 10.1590/0100-3984.2017.0115

Naik SS, Hanbidge A, Wilson SR: Radiology reports: examining radiologist and clinician preferences regarding style and content. AIR. 2001, 176:591-598. 10.2214/air.176.3.1760591

Kahn CE Jr, Langlotz CP, Burnside ES, Carrino JA, Channin DS, Hovsepian DM, Rubin DL: Toward best practices in radiology reporting. Radiology. 2009, 252:852-856. 10.1148/radiol.2523081992

European Society of Radiology: Good practice for radiological reporting. Guidelines from the Europea Society of Radiology (ESR). Insights Imaging. 2011, 2:93-96. 10.1007/S13244-011-0066-7

5. Dogan N, Varlibas ZN, Erpolat ÖP: Radiological report: expectations of clinicians. Diagn Interv Radiol. 2010, 16:179-185.

6. Scheurkogel M, Cobben L: The radiology report through the eyes of the clinician. Scientific Exhibit at European Congress of Radiology. 2013,

7. Mehta TI, Assimacopoulos A, Heiberger CJ, Weissman S, Yim D: Opinions, views, and expectations concerning the radiology report: a rural medicine report. Cureus. 2019, 11:e5822. 10.7759/cureus.5822 . Cochon LR, Kapoor N, Carrodeguas E, Ip IK, Lacson R, Boland G, Khorasani R: Variation in follow-up imaging recommendations in radiology reports: patient, modality, and radiologist predictors. Radiology. 2019, 291:700-707. 10.1148/radiol.2019182826

9. Oliveira L, Tellis R, Qian Y, Trovato K, Mankovich G: Follow-up recommendation detection on radiology reports with incidental pulmonary nodules. Studies in health technology and informatics. 2015, 216:102

10. Foster ME, Lighter DE, Godambe AV, Edgerson B, Bradley R, Godambe S: Effect of a resident physician educational program on pediatric emergency department pharmacy interventions and medication errors. Pediatr Pharmacol Ther. 2013, 18:53-62. 10.5863/1551-6776-18.1.53

11. Likic R, Maxwell SRJ: Prevention of medication errors: teaching and training. Br J Clin Pharmacol. 2009, 67:656-661. 10.1111/.1365-2125.2009.03423.x

12. Bruno MA, Walker EA, Abujudeh HH: Understanding and confronting our mistakes: the epidemiology of error in radiology and strategies for error reduction. Radiographics. 2015, 35:1668-1676. $10.1148 / \mathrm{rg} .2015150023$

13. Naveh E, Katz-Navon T, Stern Z: Resident physicians' clinical training and error rate: the roles of autonomy, consultation, and familiarity with the literature. Adv Health Sci Educ Theory Pract. 2015, 20:59-71. 10.1007/s10459-014-9508-6

14. Krupinski EA, Hall ET, Jaw S, Siegel E: Influence of radiology report format on reading time and comprehension. J Digit Imaging. 2012, 25:63-69. 10.1007/s10278-011-9424-8

15. Brady AP: Error and discrepancy in radiology: inevitable or avoidable? . Insights Imaging. 2017, 8:171-182. $10.1007 / 13244-016-0534-1$

16. Kim YW, Mansfield LT: Fool me twice: delayed diagnoses in radiology with emphasis on perpetuated errors AIR. 2014, 202:465-470. 10.2214/aj.13.11493 